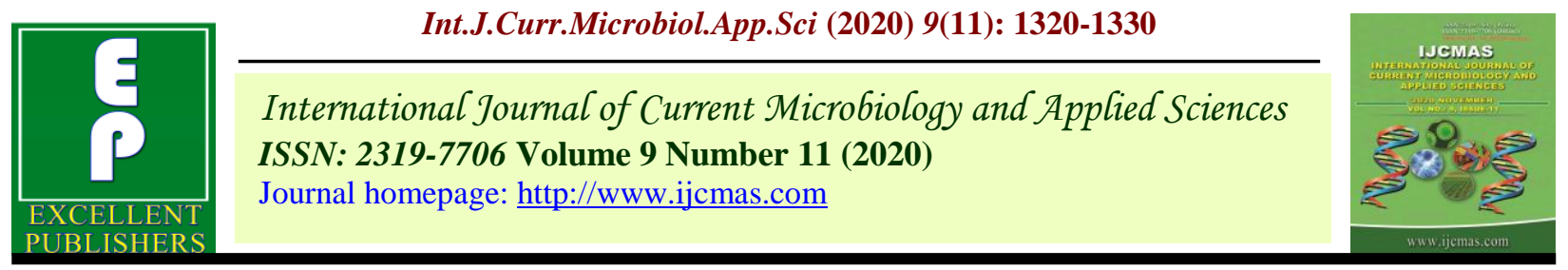

Original Research Article

https://doi.org/10.20546/ijcmas.2020.911.155

\title{
Performance of Slow Release Hydroxyapatite Coated Urea Nanofertilizer on Aerobic Paddy
}

\author{
P. Bhavani ${ }^{1^{*}}$, S. S. Prakash ${ }^{2}$, K. M. Harinikumar', \\ M. N. Thimmegowda ${ }^{3}$, P. S. Benherlal and S. B. Yoganand ${ }^{3}$ \\ ${ }^{1}$ Department of Biotechnology, ${ }^{3}$ AICRP on Dryland Agriculture, University of Agricultural \\ Sciences, GKVK, Bangalore, India \\ ${ }^{2}$ Department of Soil Science and Agriculture Chemistry, College of Agriculture V.C. Farm, \\ Mandya, Mandya, Karnataka, India \\ ${ }^{3}$ Department of Agronomy, College of Agriculture, Mandya-571402, India \\ *Corresponding author
}

\begin{tabular}{|l|}
\hline Ke y w or d s \\
Hydroxyapatite, \\
$\begin{array}{l}\text { Urea nanofertilizer, } \\
\text { Aerobic paddy, } \\
\text { Nanofertilizer }\end{array}$ \\
\hline Article Info \\
\hline $\begin{array}{l}\text { Accepted: } \\
12 \text { October } 2020 \\
\text { Available Online: } \\
10 \text { November } 2020\end{array}$ \\
\hline
\end{tabular}

\section{A B S T R A C T}

Fertilizers, irrigation and high yielding varieties contributed immensely for the success of green revolution. Increasing global food demand necessitates balanced fertilizer usage. Nitrogenous fertilizers considering the losses due to quicker release doesn't synchronize with crop demand resulting in lower crop uptake and use efficiency, necessitating nanoparticle coated urea for sustained production. Hydroxyapatite nanoparticles (HA) and urea coated hydroxyapatite nanoparticles (UHA) was synthesised through wet chemical method, were characterized using Dynamic Light Scattering (DLS), Scanning Electron Microscope (SEM), Powder X-ray Diffraction (PXRD) and Fourier Transform Infrared (FTIR) Spectroscopy. Nitrogen content of UHA particles was found to be $36.5 \%$ and diameter of nanoparticles was less than $90 \mathrm{\eta m}$. The UHA was further evaluated for its performance on aerobic paddy. Synthesized Nanofertilizer at $25 \%$ of recommended dose recorded higher grain yield in aerobic paddy. Nanofertilizer@ 50\% dose showed similar performance to $100 \%$ dose of conventional urea. The amount of fertilizer application to the environment can be reduced with nanofertilizer compared to regular dosage of conventional fertilizer without compromising the crop yield thereby reducing environmental pollution of water and soil.

\section{Introduction}

Conventional fertilizers along with irrigation and high yielding varieties have contributed immensely for green revolution. Intensive agriculture during post green revolution has put extensive burden on soil removing most of the nutrients resulting in nutrient deficient soils. Though the soils have been restored with nutrients time and again using inorganic fertilizers, farm yard manure and green manures; Indian soils have particularly displayed nitrogen deficiency with $99 \%$ of soils responding to nitrogen application. To address this issue and to boost productivity, measures were taken to encourage the use of inorganic fertilizers. As a result, $\mathrm{N}$ fertiliser use grew from meagre amount of about 0.45 $\mathrm{kg} \mathrm{ha}{ }^{-1}$ in $1950-51$, to nearly $87 \mathrm{~kg} \mathrm{ha}^{-1}$ in 2014-15 [Chander, 2016]. 
Conventional bulk fertilizers in general have low nutrient uptake efficiencies necessitating the usage of fertilizers in large quantities. In spite of regular application, available nitrogen in $90 \%$ of arable soil is reported to be deficient as nitrogen is subject to excessive losses through volatilization, run off, leaching and denitrification [Manikandan and Subramanian, 2014]. Owing to continuous use of inorganic fertilizers and their susceptibility to undue losses; they have become potential sources to pollute soil, water and air though emission of greenhouse gases and eutrophication. In recent years, efforts are underway to minimize pollution due to fertilizers by altering agricultural practices, using nitrification inhibitors and the use of the new improved fertilizers. Advancements in nanotechnology have opened up novel solutions to address various agricultural problems through synthesis of smart fertilizers which enable plants to absorb nutrients effectively [Raliya, Saharan, Dimkpa \& Biswas 2017].

Nanostructured formulations with altered physicochemical properties can be probable solution to the current problems through mechanisms such as targeted delivery or slow/controlled release mechanisms and trigger controlled-conditional release [Guru et al., 2015].

Nanostructured formulations are structured to deliver nutrients to plants allowing controlled or slow release of active ingredients resulting in efficient uptake [Raliya et al., 2017]. Since nanoscale particles are smaller in dimension compared to bulk particles, the plants can absorb them with different dynamics than bulk particles or ionic salts, which presents an added advantage. There is a need for design and synthesis of nanofertilizers to tailor the need of diverse soil, environmental and crops. The use of nanofertilizers is reported to increase fertilizer use efficiency minimizing the potential negative effects associated with over dosage which reduces the frequency of the application [Kottegoda et al., 2011]. Nanofertilizers mainly delay the release of the nutrients and extend the fertilizer effective period [Naeem et al., 2017]. However, environmental health and safety aspects of nanotechnology should also be considered, and it is crucial to determine the toxicity / biocompatibility of nanofertilizers.

There are many attempts to synthesise, nanocapsules, nanocomposites, nanohybrids mainly to sustain nitrogen release and enhance use efficiency in the form of slow release and controlled-release fertilizers [Shaviv 2000; Tarafdar and Subramaniam 2011; Xiaoyu et al., 2013; Manikandan \& Subramanian 2014; 2016]. N fertilizers with controlled release characteristics have been synthesized using the adsorbents zeolite, halloysite, montmorillonite and bentonite nanoclays [Manikandan \& Subramanian 2014]. Kottegoda et al., [2011] have synthesized by encapsulating urea coated hydroxyapatite nanoparticles in wood Glyricidia sepium while Subbaiya et al., [2012] have used both chemical and biological method of synthesis. These methods have lengthy process and difficult to scale up, hence a simple method of nanofertilizer production amenable for large scale production and testing its applicability in crop production can help for upscaling this futuristic technology. With this background, research was undertaken to synthesize urea coated hydroxyapatite nanofertilizer for enhanced nitrogen use efficiency and its filed testing using aerobic rice as test crop.

\section{Materials and Methods}

\section{Synthesis of hydroxyapatite nanoparticles}

All the reagents used in this experiment were purchased from HiMedia and of analytical grade. Hydroxyapatite nanoparticle was synthesized using chemical synthesis process 
as described by Mateus et al., [2007] using aqueous solution of calcium hydroxide and orthophosphoric acid $\left(\mathrm{H}_{3} \mathrm{PO}_{4}, 85 \%\right)$. $1 \mathrm{~L}$ aqueous solution of $1 \mathrm{M}$ calcium hydroxide was prepared and $1 \mathrm{~L}$ of $0.6 \mathrm{M}$ orthophosphoric acid was added drop-wise with continuous stirring on a magnetic stirrer at room temperature. The suspension obtained was washed with deionised water and dried at $100^{\circ} \mathrm{C}$ for $24-48 \mathrm{hrs}$ and nanoparticles were characterized using DLS, EDS, PXRD, SEM and FTIR.

\section{Synthesis of urea coated hydroxyapatite nanoparticles}

Urea coated hydroxyapatite nanoparticle was synthesised by modifying the method of Kottegoda et al., [2017]. The white solution of hydroxyapatite nanoparticle was added to $100 \mathrm{ml}$ of saturated urea solution (approx. $300 \mathrm{~g})$. The suspension was constantly stirred for 12 hours at $1000 \mathrm{rpm}$ at room temperature. The urea-hydroxyapatite solution was allowed to settle and the excess liquid was drained out. The urea modified nanofertilizer was washed and dried at $65^{\circ} \mathrm{C}$ for one to two weeks. Further, characterization was done using DLS, PXRD, SEM and FTIR.

\section{Nitrogen estimation}

The nitrogen content of urea coated HA nanoparticle was determined by Kjeldahl's method. A sample of $0.5 \mathrm{~g}$ was digested using concentrated $\mathrm{H}_{2} \mathrm{SO}_{4}$ and a digestion mixture (containing $\mathrm{K}_{2} \mathrm{SO}_{4}$ and $\mathrm{CuSO}_{4} \quad 5 \mathrm{H}_{2} \mathrm{O}$ and selenium in the proportion of 100:20:1) and was distilled in alkaline medium. The liberated $\mathrm{NH}_{3}{ }^{+}$was trapped in boric acid and titrated against standard $\mathrm{H}_{2} \mathrm{SO}_{4}$ as described by [Jackson 1973].

\section{Characterization of synthesized nanoparticles using Powdered XRD, SEM, FTIR}

Powder X-ray diffraction patterns of the synthesized samples were obtained using Rigaku Ultima IV X-ray powder diffractometer using $\mathrm{Cu}-\mathrm{K} \alpha$ radiation $(\lambda=0.154 \mathrm{~nm})$ over $2 \theta$ range of $10-90^{\circ}$, with a step size of $0.02^{\circ}$ and a step time of $2 \mathrm{~s}$. Stability of synthesized nanoparticles were analyzed by measuring zeta potential using Microtac Flex. PXRD and zeta potential analysis was carried out at University of Mysore.

Scanning electron microscopy was done using Carl Zeiss Ultra 55 FE-SEM for morphological analysis and determination of particle size. Fourier Transform Infrared Spectroscopy was done using Perkin Elmer Spectrum v 10.03.09 software to analyze functional groups and molecular bonding of synthesized samples. SEM and FTIR were carried out at CeNSe, Indian Institute of Sciences, Bengaluru.

\section{Experimental design for Pot experiments}

The pot experiments were conducted in the College of Agriculture, Mandya during the year 2016-18. The experiment was conducted to differentiate the influence of varying doses of urea modified hydroxyapaptite nanofertilizer and recommended doses of conventional urea on growth and yield parameters of aerobic rice varieties BI33 (Anagha) and KMP175 (Daksha).

The growth medium used was sandy loam soil. The soil was collected from completely pulvarized plot and was processed by removing stone and stubbles. The soil was completely mixed and soil samples were drawn. After mixing the soil, each pot was loaded with $7 \mathrm{~kg}$ of soil and was watered.

The soil samples drawn were used for estimation of electrical conductivity, $\mathrm{pH}$ and soil Nitrogen content. Soil $\mathrm{pH}$ was measured at $1: 1.25$ soil to water ratio using $\mathrm{pH}$ meter 
with calomel glass electrode assembly.

Electrical conductivity of soil sample after addition of $100 \mathrm{ml}$ distilled water to $1 \mathrm{~g}$ soil samples was measured by conductivity meter. Total nitrogen content in soil samples was determined by the method of micro-Kjeldahl method [Jackson, 1973].

The pot experiment was laid in complete randomized design (CRD) with six treatments (Rec. N, absolute control (0 N), Nanofertilizer @ 25, 50, 75 and $100 \mathrm{~kg} \mathrm{~N}$ eq) and four repetitions each. For optimal growth, paddy needs 100:50:50 kg N, $\mathrm{P}_{2} \mathrm{O}_{5}, \mathrm{~K}_{2} \mathrm{O}$ ha $^{-1} \mathrm{~N}$, as recommended in package of practises by UAS, Bengaluru, Karnataka, corresponding to $543 \mathrm{mg} \mathrm{N}, 0.78 \mathrm{mg} \mathrm{P}$ and $208 \mathrm{mg} \mathrm{K}$ per pot. The pot with complete recommended dose of fertilizer was kept as positive control and pot with no nitrogen supply was kept as negative control.

\section{Planting material}

Aerobic rice was selected as experimental crop mainly because paddy is staple food and is consuming major portion of fertilizers. Of late, due to scarcity of water resources, paddy cultivation is facing hindrances and farmers are looking for alternative methods like aerobic rice. Application of nitrogenous fertilizers faces greater losses under non water logged conditions due to denitrification. To address this issue, aerobic rice was selected as an experimental crop. Paddy seeds of variety BI 33 were collected from aerobic rice lab, Advanced Centre for Plant Biotechnology, UAS, GKVK, Bengaluru and KMP seeds were collected from AICRP on Paddy, Zonal Agricultural Research Station, V.C. Farm, Mandya.

\section{Sowing}

BI 33 was sown in February 2017 in pots at the rate of two seeds per pot. KMP175 was sown during November 2017. Calculated fertilizer according to the treatments was mixed with one $\mathrm{kg}$ soil was filled to the pots, after fertiliser application sowing was taken. The pots were then equally watered and were exposed to greenhouse sunlight.

\section{Measurement of plant growth and yield parameters and data analysis}

Following germination, plants were thinned to one plant per pot. Plant height, numbers of leaves, number of tillers, flag leaf length, panicle weight, panicle length, chlorophyll content, number of seeds per plant, total number of seeds, seed weight and Biomass weight was recorded adopting standard procedure. Data were analyzed statistically through one-way ANOVA in a general linear model.

\section{Nitrogen release pattern}

To study the nitrogen release pattern, an experiment was designed according to Manikandan and Subramanian [2014]. Small pots were filled with soil homogenised with urea and UHA as treatments.

The $100 \mathrm{ml}$ of deionised water added from 1 to 40 days. Solutions were collected to determine nitrogen content in the water.

\section{Results and Discussion}

\section{Synthesis and characterisation of the urea- coated hydroxyapatite nanoparticles}

Hydroxyapatite and urea coated hydroxyapatite nanoparticles were analyzed using DLS, PXRD, SEM and FTIR. Per cent of calcium and phosphorous in hydroxyapatite nanoparticles was found to be $35 \%$ and $11 \%$ following energy dispersive X-ray spectroscopy. Urea coated hydroxyapatite nanoparticle showed good stability in the solution and recorded $135 \mathrm{mV}$ zeta potential as indicated by dynamic light scattering. The PXRD pattern obtained was similar to the 
powder diffraction file for HA (ICDD PDF No. 09-0432) and urea coated nanoparticles showed similarity to the peaks obtained by Kottegoda et al., [2011]. Peak corresponding to urea was observed in urea-hydroxyapatite PXRD pattern (Fig. 1). SEM images of HA particles indicated oblong rice grain shaped morphology with size range between 25-55 $\eta \mathrm{m}$. Upon coating with urea the morphological shape remained same with size varying from 45-65 $\mathrm{\eta m}$ (Fig. 2 and 3).

FTIR spectrum obtained describes hydroxyapatite nanoparticles and urea modification of HA nanoparticles. The sharp intense narrow band @ $1030 \mathrm{~cm}^{-1}$ correspond to symmetric stretching mode of $\left[\mathrm{PO}_{4}{ }^{3-}\right] \mathrm{v}_{3}$ ions in hydroxyapatite. Broadened $[\mathrm{OH}]$ stretching absorption was observed @ $3372 \mathrm{~cm}^{-1}$ and $632 \mathrm{~cm}^{-1}$ indicating polymeric association of hydrogen bonding. Narrow double peak@605 $\mathrm{cm}^{-1}$ indicates asymmetric and symmetric deformation modes of $\left[\mathrm{PO}_{4}{ }^{3-}\right.$ ] $\mathrm{v}_{4}$ group (P-O-P). An absorption band of weak intensity @ $2177 \mathrm{~cm}^{-1}$ is connected with combinations of $\left[\mathrm{PO}_{4}{ }^{3-}\right] \mathrm{v}_{3}, \mathrm{v}_{1}$ modes. These functional groups correspond to nonstoichiometric apatite HAp structure with a low crystallinity degree. Bonding environment of urea coated HA nanoparticles with HA is indicated by change in the peaks position. $\mathrm{N}-\mathrm{H}$ stretching frequency is observed as doublet @ $3437 \mathrm{~cm}^{-1}$ and 3329 $\mathrm{cm}^{-1}$ with significant broadened peak indicating asymmetric and symmetric N-H stretching respectively. Moderate intensity broad peak @ $1615 \mathrm{~cm}^{-1}$ indicates strong N-H bending absorptions of primary and secondary amines. Weak narrow peak @1674 cm ${ }^{-1}$ correspond to carbonyl group and medium intensity broadened peak@1461 cm ${ }^{-1}$ indicate N-C-N stretching in urea. The functional groups observed in FTIR spectra indicate physical adsorption of urea onto hydroxyapatite nanoparticles (Fig. 4).

\section{Nitrogen content}

Urea coated HA nanoparticles were analysed for $\mathrm{N}$ content twice and found that the material contain 36 per cent $\mathrm{N}$ as against 46 per cent in conventional urea fertilizer. Kottegoda et al., (2011) reported $33.2 \% \mathrm{~N}$ content in the urea surface-modified nanoparticles, while Subbaiya et al., (2012) reported $35 \% \mathrm{~N}$ in nanourea modified hydroxyapatite nanoparticles. In another study, Manikandan and Subramanian (2014) reported $28 \% \mathrm{~N}$ in nanoporous zeolite based urea fertilizer.

\section{Effect of nano-fertilizer on the growth and development of paddy}

\section{Soil parameters}

The properties of the soil used for study was evaluated and is presented in the table below:

\begin{tabular}{|c|c|c|c|}
\hline & $\mathrm{N}(\%)$ & $\mathrm{pH}$ & $\mathrm{EC}\left(\mathrm{dS} \mathrm{m}^{-1}\right)$ \\
\hline Season 1 & 0.013 & 7.8 & 0.41 \\
\hline Season 2 & 0.015 & 8.7 & 0.32 \\
\hline
\end{tabular}

The soil used during the first season has medium nitrogen content $(0.013 \%$ equivalent to $291 \mathrm{~kg} / \mathrm{ha}$ ) and neutral to saline soil reaction and normal conductivity, while soil of the second season showed alkaline soil reaction and medium nutrient content $(0.015 \%$ equivalent to $336 \mathrm{~kg} / \mathrm{ha})$.

\section{Observations on plant growth and yield parameters}

Several studies have reported beneficial effect of nanofertilizer on plant growth. Nanofertilizer application in rice that promoted the growth, development, total phenolic content 
and antioxidant properties demonstrating the potential to improve crop production and plant nutrition [Benzon et al., 2015]. The pot experiment was conducted for two consecutive seasons on the aerobic rice varieties BI 33 and KMP 175 to evaluate the effect of urea coated hydroxyapatite nanofertilizer and the results were compared with the recommended dose of conventional neem coated urea. The results clearly indicated that the newly synthesized nano- fertilizer showed on par results on growth and yield parameters of aerobic rice varieties compared with conventional urea. In BI33, the yield attributes viz., panicle weight, number of seeds per panicle, plant height, number of leaves, number of tillers were significantly superior with nanofertilizer at $50 \%$ or $75 \% \mathrm{~N}$ equivalent compared to the control (N0), but was on par with $100 \% \mathrm{~N}$ through conventional fertilizer.

Table.1 EDS profile of hydroxyapatite and urea-coated hydroxyapatite nanoparticle

$\begin{array}{lll}\begin{array}{l}\text { Element } \\ (\%)\end{array} & \text { Hydroxyapatite } & \begin{array}{l}\text { Urea-modified } \\ \text { Hydroxyapatite }\end{array} \\ \mathrm{N} & - & 36.5 \\ \mathrm{Ca} & 35.43 & 12.6 \\ \mathrm{P} & 11.94 & 5.4\end{array}$

Table.2 Effect of urea coated hydroxyapatite nanofertilizer on yield and yield attributes of BI33, aerobic rice

\begin{tabular}{|l|c|c|c|c|c|c|c|c|}
\hline Treatment & $\begin{array}{c}\text { Panicle } \\
\text { length }\end{array}$ & $\begin{array}{c}\text { Panicle } \\
\text { weight }\end{array}$ & $\begin{array}{c}\text { No. of } \\
\text { seeds per }\end{array}$ & $\begin{array}{c}\text { Seed } \\
\text { weight }\end{array}$ & $\begin{array}{c}\text { Plant } \\
\text { paicle }\end{array}$ & $\begin{array}{c}\text { Number } \\
\text { (g)ight }\end{array}$ & $\begin{array}{c}\text { Number } \\
\text { of leaves }\end{array}$ & $\begin{array}{c}\text { Number } \\
\text { of tillers } \\
\text { of filled } \\
\text { grains }\end{array}$ \\
\hline N0:50P:50K & 12.85 & 3.70 & 203.00 & 13.57 & 84.58 & 22.83 & 10.33 & 180.33 \\
\hline N100:50P:50K & 15.19 & 6.26 & 285.33 & 16.04 & 89.50 & 25.67 & 12.17 & 292.00 \\
\hline NF25:50P:50K & 15.14 & 5.29 & 243.00 & 14.81 & 87.06 & 22.11 & 11.39 & 216.00 \\
\hline NF50:50P:50K & 15.01 & 5.12 & 281.00 & 15.76 & 89.19 & 32.50 & 12.00 & 242.00 \\
\hline NF75:50P:50K & 14.78 & 5.53 & 295.67 & 15.53 & 90.28 & 23.78 & 11.44 & 267.67 \\
\hline N100:50P:50K & 15.07 & 4.80 & 222.33 & 14.76 & 85.90 & 23.33 & 11.33 & 201.33 \\
\hline S.Em.土 & 0.62 & 0.31 & 20.42 & 0.76 & 3.38 & 1.99 & 0.82 & 10.05 \\
\hline CD (p=0.05) & 1.87 & 0.93 & 61.93 & 2.31 & 10.24 & 6.04 & 2.49 & 30.49 \\
\hline CV (\%) & 4.28 & 6.76 & 8.69 & 5.24 & 3.91 & 8.25 & 7.29 & 4.79 \\
\hline
\end{tabular}


Table.3 Effect of urea coated hydroxyapatite nanofertilizer on yield and yield attributes of KMP 175 , aerobic rice

\begin{tabular}{|c|c|c|c|c|c|c|c|c|}
\hline Treatment & $\begin{array}{c}\text { Panicle } \\
\text { length } \\
\text { (cm) }\end{array}$ & $\begin{array}{c}\text { Flag leaf } \\
\text { length } \\
\text { (cm) }\end{array}$ & $\begin{array}{c}\text { Biomass } \\
\text { weight } \\
\text { (g/plant) }\end{array}$ & $\begin{array}{c}\text { Seed } \\
\text { weight } \\
\text { (g) }\end{array}$ & $\begin{array}{c}\text { Plant } \\
\text { height } \\
\text { (cm) }\end{array}$ & $\begin{array}{c}\text { Number } \\
\text { of leaves }\end{array}$ & $\begin{array}{c}\text { SPAD } \\
\text { value }\end{array}$ & $\begin{array}{c}\text { Number } \\
\text { of filled } \\
\text { grains }\end{array}$ \\
\hline N0:50P:50K & 17.55 & 51.19 & 16.44 & 9.27 & 90.25 & 10.50 & 33.99 & 86.50 \\
\hline N100:50P:50K & 17.69 & 53.06 & 17.38 & 15.12 & 92.00 & 13.00 & 34.85 & 111.61 \\
\hline NF25:50P:50K & 18.10 & 50.88 & 16.25 & 12.29 & 94.50 & 13.50 & 34.51 & 103.05 \\
\hline NF50:50P:50K & 18.41 & 53.73 & 14.88 & 14.99 & 91.38 & 12.00 & 34.23 & 114.11 \\
\hline NF75:50P:50K & 18.65 & 53.44 & 12.79 & 14.36 & 95.63 & 11.25 & 34.29 & 112.39 \\
\hline N100:50P:50K & 19.25 & 52.33 & 13.50 & 14.53 & 94.13 & 11.38 & 35.49 & 110.24 \\
\hline S.Em. 5 & 0.29 & 0.46 & 0.29 & 0.21 & 0.53 & 0.20 & 0.41 & 0.85 \\
\hline CD (p=0.05) & 0.89 & 1.39 & 0.89 & 0.65 & 4.97 & 1.89 & 1.23 & 2.57 \\
\hline CV (\%) & 12.80 & 11.85 & 14.06 & 10.92 & 10.31 & 10.94 & 12.90 & 15.35 \\
\hline
\end{tabular}

Fig.1 Powder X-ray diffraction pattern of (a) synthesized hydroxyapatite nanoparticles (b) urea coated hydroxyapatite nanoparticles

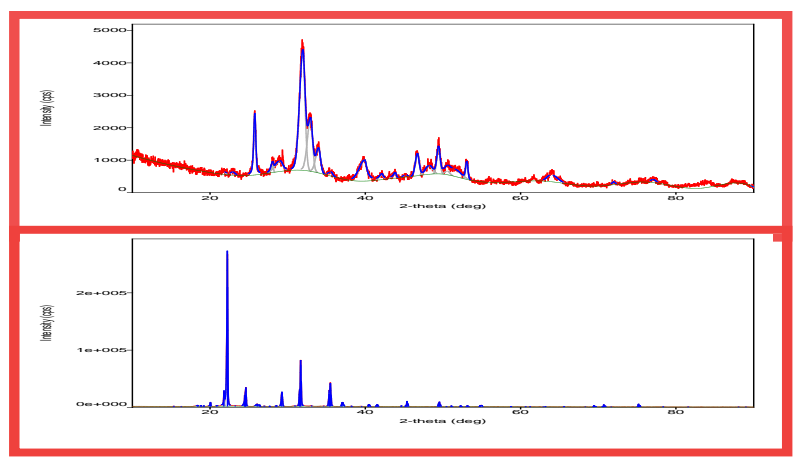

Fig.2 Scanning Electron microscopic image of (a) synthesized hydroxyapatite nanoparticles (b) urea coated hydroxyapatite nanoparticles

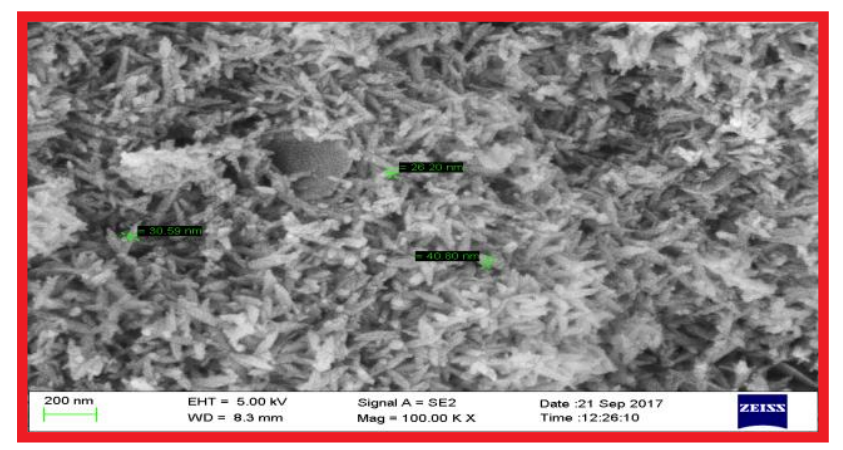


Fig.3 Particle size distribution of synthesized hydroxyapatite nanoparticle

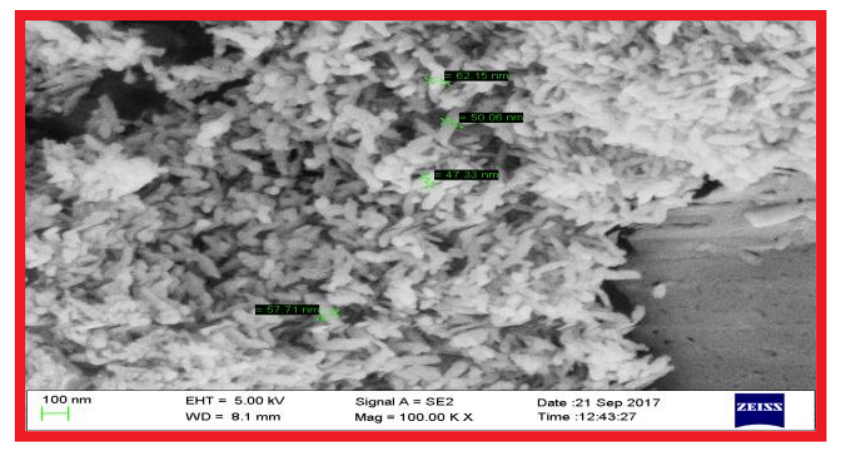

Fig.4 Fourier transform infrared spectra of (a) synthesised hydroxyapatite nanoparticles (b) urea coated hydroxyapatite nanoparticles

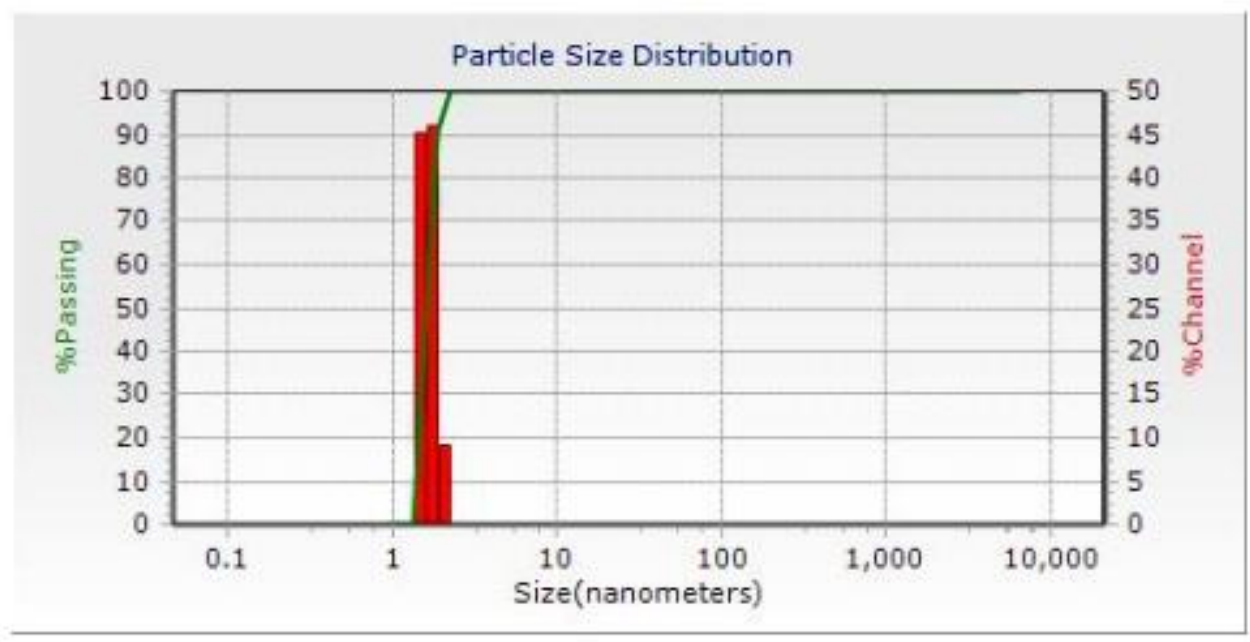

Fig.5 Effect of urea coated hydroxyapatite nanofertilizer on seed weight of aerobic rice varieties

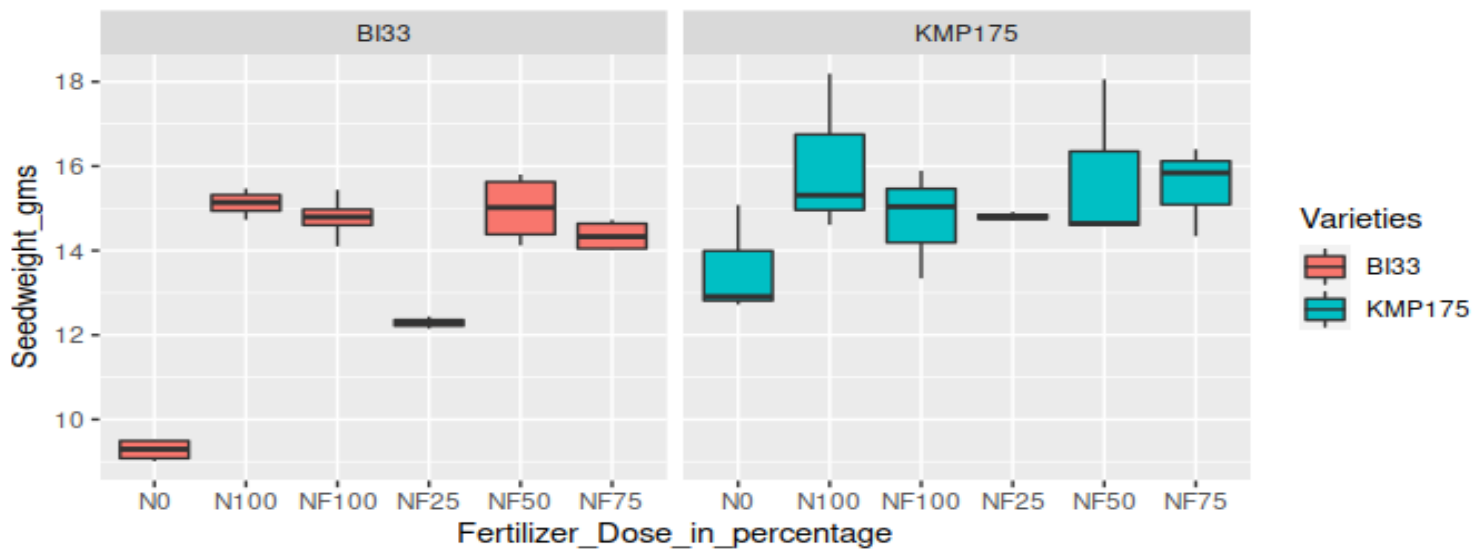


Fig.6 Elution profile of conventional urea and urea-coated hydroxyapatite nanoparticle

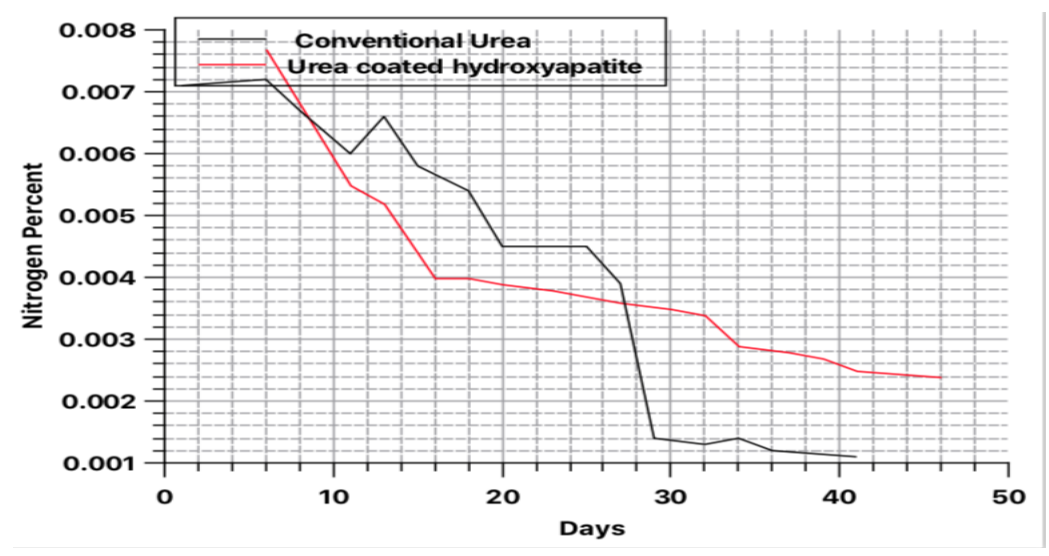

The seed weight was higher with $100 \%$ conventional fertilizer (16.04 g), but was statistically at par with different levels of nanofertilizer. Among the nanofertilizers, $50 \% \mathrm{~N}$ equivalent showed higher seed weight $(15.76 \mathrm{~g} /$ plant $)$ followed by $75 \% \mathrm{~N}(15.33$ g/plant). In KMP 175, panicle length, flag leaf length, plant height and number of filled grains per panicle was significantly higher with nanofertilizer with 50 and $75 \% \mathrm{~N}$ equivalent compared to control (N0). However, it was on par with $100 \% \mathrm{~N}$ through conventional fertilizer. Although, higher values of biomass weight, seed weight, and number of leaves were recorded with recommended conventional $100 \% \mathrm{~N}$ fertilizer, it was at par with nanofertilizers at different levels.

The superiority in the yield parameters with nanofertilizers is associated with betterment of growth parameters viz., plant height, chlorophyll indicated with SPAD. Similar results of nanonutrition in rice were noticed by Benzon et al., [2015]. The enhanced growth in aerobic rice with $50 \% \mathrm{~N}$ and $75 \% \mathrm{~N}$ at par with $100 \%$ conventional fertilizer is associated with better nutrient availability and uptake leading to improved nitrogen use efficiency. These suggest that nanofertilizer can either provide nutrients for the plant or aid in the transport or absorption of available nutrients resulting in better crop growth. Related study by Liu and Lal [2015]revealed similar findings in soybean. Nitrogen being a component in chlorophyll, efficient nitrogen utilization with lower dose of nanofertilizer improved the photosynthetic rate and assimilation resulting in better growth and yield attributes, These results are in harmony with those reported by Benzon et al., [2015]; Jyothi and Hebsur [2017].

However, UHA nano-fertilizer at 50\%, 75\%, $100 \%$ dosage did not show significant differences in growth and yield, in fact plants performance decreased relatively at $100 \%$ dosage. This might be associated with the saturation of nitrogen demand of rice at $75 \% \mathrm{~N}$ with nanofertilizer formulation. Further, increased $\mathrm{n}$ levels followed Mitscherlich yield equation. The results are presented in Table 1, 2 and 3.

\section{Nitrogen release pattern}

Nitrogen release was quicker from soil containing conventional urea while UHA containing soil showed gradual release which indicates that the synthesized nanofertilizer releases the nutrient in step-by-step manner. 
In conclusion the nanofertilizer composed of $<90 \mathrm{~nm}$ size urea-coated hydroxyapatite nanoparticles with $36 \%$ nitrogen was synthesized and was characterized using DLS, XRD, SEM and FTIR. The synthesized nanofertilizer showed equivalent performance to $100 \%$ conventional urea. Therefore, the current fertilizer dosage recommended for aerobic rice varieties can be reduced without compromising yield. However, the further studies are required to confirm the results under field conditions. The study indicates the improvement of fertilizer use efficiency by reducing nitrogen losses in an eco-friendly manner and to reduce environmental pollution.

\section{Acknowledgements}

The authors thank University of Agricultural Sciences, Bangalore for the financial support to carry out the research work and AICRP on Paddy, Zonal Agricultural Research Station, V.C. Farm, Mandya for providing seeds.

\section{Declaration of interest statement}

There is no conflict of interest exists among the authors.

\section{References}

Benzon, H., Rosnah, U., Venecio, U. and Lee, S. C. (2015). Nano-fertilizer affects the growth, development and chemical properties of rice., International Journal of Agronomy and Agricultural Research, 7(1): 105-117.

Chander, S. (2016). Nitrogen in Indian Agriculture., Indian Journal of Fertilizers, pp. 12-13.

Guru, T., Veronica. N; Thatikunta, R. and Reddy, S. N. (2015). Crop Nutrition Management with Nano fertilizers., International Journal of Environmental Science and Technology, 1(1): 4-6.
Jackson, M. (1973). Soil Chemical Analysis, Prentice Hall of India Pvt. Ltd., New Delhi, p. 38-56. .

Jyothi, T. and Hebsur, N. (2017). Effect of nanofertilizers on growth and yield of selected cereals - A review, Agricultural Reviews, 38 (2): 112-120.

Kottegoda, N., Munaweera, I., Madusanka, N. and Karunaratne, V. (2011). A green slow-release fertilizer composition based on urea-modified hydroxyapatite nanoparticles encapsulated wood., Current Science, Vol. 101, No. 1, pp. 73-78.

Kottegoda, N., Sandaruwan, C., Priyadarshana, G., Siriwardhana, A., Rathnayake, U. A., Berugoda Arachchige, D. M., Kumarasinghe, A. R., Dahanayake, D., Karunaratne, V. and Amaratunga, G. A. J. (2017). UreaHydroxyapatite Nanohybrids for Slow Release of Nitrogen, ACS Nano 11 : 1214-1221.

Liu, R. and Lal, R. (2015). Potentials of engineered nanoparticles as fertilizers for increasing agronomic productions. A review., Science of the Total Environment 514, 131-139. .

Manikandan, A. and Subramanian, K. S. (2014). Fabrication and characterisation of nanoporous zeolite based $N$ fertilizer., African Journal of Agricultural Research. Vol. 9(2), pp. 276-284. .

Manikandan, A. and Subramanian K. S. (2016). Evaluation of Zeolite Based Nitrogen Nano-fertilizers on Maize Growth, Yield and Quality on Inceptisols and Alfisols., International Journal of Plant \& Soil Science. 9(4): 19.

Mateus, A. Y. P., Barrias, C. C., Ribeiro, C., Ferraz, M. P. and Monteiro, F. J. (2007). Comparative study of nanohydroxyapatite microspheres for medical applications., Journal of 
Biomedical and Material Research A, 86: 483-493.

Naeem, M., Ansari, A. and Gill, S., 2017. Essential Plant Nutrients: Uptake, Use Efficiency, and Management. Springer International Publishing.

Raliya, R., Saharan, V., Dimkpa, C. and Biswas, P. (2017). Nanofertilizer for Precision and Sustainable Agriculture: Current State and Future Perspectives, Journal of Agriculture and Food Chemistry, 66: 6487-6503.

Shaviv, A. (2000). Advances in Controlled Release of Fertilizers, Advances in Agronomy 71: 1-49.

Subbaiya, R., Priyanka, M. and Masilamani
S., M. (2012). Formulation of Green Nano-Fertilizer to Enhance the Plant Growth through Slow and Sustained Release of Nitrogen., Journal of Pharmacy Research. 5(11): 5178-5183.

Tarafdar, J. and Subramaniam, K. (2011). Prospects of nanotechnology in Indian farming, Indian Journal of Agricultural Sciences $81: 887-893$.

Xiaoyu Ni Wu; Yue-Jin Wu; Zhengyan Lin; $\mathrm{Wu}$ Guannan, Q. and Lixiang, Y. (2013). A novel slow-release urea fertiliser: Physical and chemical analysis of its structure and study of its release mechanism, Biosystems Engineering, 115: 274-282

\section{How to cite this article:}

Bhavani, P., S. S. Prakash, K. M. Harinikumar, M. N. Thimmegowda, P. S. Benherlal and Yoganand, S. B. 2020. Performance of Slow Release Hydroxyapatite Coated Urea Nanofertilizer on Aerobic Paddy. Int.J.Curr.Microbiol.App.Sci. 9(11): 1320-1330. doi: https://doi.org/10.20546/ijcmas.2020.911.155 